\title{
Synthesis and characterization of mixed nano fertilizer influencing nutrient use efficiency, productivity, and nutritive value of tomato fruits
}

\footnotetext{
Md. Hafizur Rahman ${ }^{1,2}$, Md. Nazmul Hasan ${ }^{1,2}$, Shireen Nigar ${ }^{3}$, Fanyi Ma ${ }^{4}$, Mohamed Aly Saad Aly ${ }^{5}$ Md. Zaved Hossain Khan ${ }^{1,2 *}$

${ }^{1}$ Department of Chemical Engineering, Jashore University of Science and technology, Jashore 7408, Bangladesh

${ }^{2}$ Laboratory of Nano-bio and Advanced Materials Engineering (NAME), Jashore University of Science and technology, Jashore 7408, Bangladesh

${ }^{3}$ Department of Nutrition and Food Technology, Jashore University of Science and Technology, Jashore, Bangladesh

${ }^{4}$ Key Laboratory of Natural Medicine and Immuno-Engineering of Henan Province, Henan University, Kaifeng, 475004, China

${ }^{5}$ Department of New Biology, Daegu Gyeongbuk Institute of Science and Technology (DGIST), 333 Techno jungang-daero, Daegu 42988, Republic of Korea.

*Corresponding Author: Dr. Md. Zaved Hossain Khan;

Email: zaved.khan@yahoo.com; namelab.che.just@ gmail.com

(iD) https://orcid.org/0000-0001-9353-6469;
} 


\section{SI-1 Visual Presentation of Experimental Growing Periods of Tomato and Tomato Fruits}
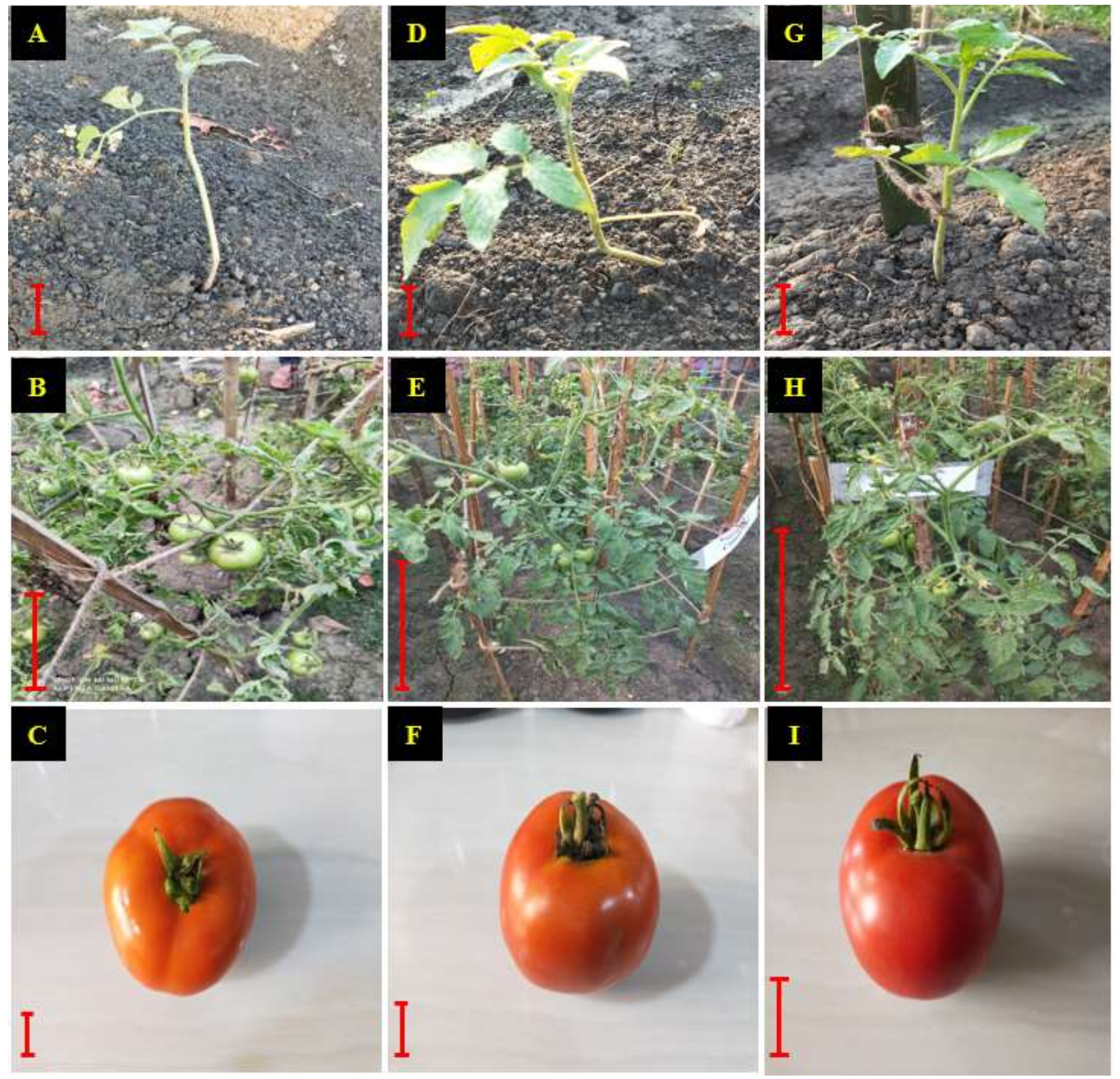

Figure S1 Visual presentation of blank treatment (A-C), Commercial fertilizer treatment (D-F), and foliar application of MNF with CF treatment (G-I) representing the growth stage (A, D and $\mathrm{G})$, fruiting stage $(\mathrm{B}, \mathrm{E}$ and $\mathrm{H})$ and ripe tomatoes of all treatments $(\mathrm{C}, \mathrm{F}$ and $\mathrm{I})$. 